\title{
Anterior Cervical Arachnoid Cyst
}

\author{
Abolfazl Rahimizadeh, Give Sharifi \\ Department of Neurosurgery, Pars Hospital, Tehran, Islamic Republic of Iran
}

This report is composed of two patients with anteriorly located cervical intradural arachnoid cyst and review of 24 cases in Englishlanguage literature. Both of our patients were in the first two decades of life with neck pain and motor weakness. With suspicious diagnosis of anterior arachnoid cyst surgery was carried out in both cases, though laminectomy in one and laminoplasty in the other. The cyst wall was widely fenestrated with subsequent subtotal excision of the cyst. Both cases had good long-term outcome. The review disclosed male predominance. $73 \%$ of the patients were diagnosed within the first two decades of life. Neck pain and motor weakness were the dominant signs and symptoms of this pathology. Magnetic resonance imaging showing a cerebrospinal fluid (CSF) containing cyst was the best mode of diagnosis. Wide cyst fenestration with waying CSF into subarachnoid cyst was the most appropriate and applied surgery with optimal outcome.

Keywords: Cervical; Arachnoid cyst; Intradural; Review of the literature; Spinal

\section{Introduction}

Intradural arachnoid cysts are uncommon and arise in thoracic, lumbar and cervical region in decreasing frequency. Arachnoid cyst are mostly located on the posterior aspect of the cord. This means that anteriorly located arachnoid cyst are exceptional, particularly those occurring in the cervical spinal region [1]. Regarding the rarity of this pathology in this certain location, it should be noted that eight out of nine cases of intradural arachnoid cyst reported by Kendall et al. [1] lied posteriorly in the thoracic region. Moreover, of 17 cases of intradural arachnoid cyst including eight cases of cervical region reported by Alvisi et al. [2], all were located posteriorly. A literature search by Kazan et al. [3] from 1974 to 1999 revealed only 10 cases of anterior cervical intradural arachnoid cyst including two cases of their own. However, apparently six cases escaped their attention $[1,4]$. In current article, besides very careful resurvey of the literature up to 1999 , we updated the review yielding 24 cases reported in English literature [1,3-21]. Herein, two additional cases who have undergone surgery with good postoperative neural recovery are presented.

\section{Case Report}

\section{Case 1}

This 2-year-old girl was admitted to our hospital with a 2-week history of torticollis and weakness of the left upper extremity for a week. She had no history of trauma or infection of upper respiratory tract infection. Her neurological exam showed moderate paresis of the left upper extremity, all reflexes were hyperactive and plater reflex was extensor on the left side. Cervical spine X-Ray and open mouth view were regarded normal. Magnetic reso-

Received Jan 19, 2012; Revised May 15, 2012; Accepted Jun 2, 2012

Corresponding author: Abolfazl Rahimizadeh

Department of Neurosurgery, Pars Hospital, No. 83-Keshawarz Blvd, 14154 Tehran, Islamic Republic of Iran

Tel: +98-21-88-66-12-44, Fax: +98-21-88-79-85-03, E-mail: a_rahimizadeh@hotmail.com 
nance imaging (MRI) revealed an intradural hypointense cystic mass anterior to the cord in $\mathrm{T} 1$ and hyperintense in T2 images resembling cerebrospinal fluid (CSF) intensity at C5-C6 level which was markedly compressing the cord (Fig. 1). A provisional diagnosis of intradural arachnoid cyst was made.

With the patient in prone position laminectomy of C5 and C6 was done. The dura was tense and on opening the cord was flattened and budged posteriorly into the dural incision. The dentate ligaments at C5-C6 level were cut on the left side revealing a translucent cystic collection anterior to the cord. The cyst was aspirated revealing CSF. Following aspiration, the cyst shrunk and the cord pulsation appeared. With gentle retraction of the cord, the cyst's capsule could be excised totally. Postoperatively, the child showed motor recovery and her neurological examination three months after surgery was normal.

\section{Case 2}

This 17-year-old male was referred with dull moderate neck pain followed with progressive weakness of the right upper extremity of one month duration followed by gait disturbances in recent days. On clinical survey, he was found to have quadriparesis most prominent in the right upper extremity. Cervical MRI disclosed a ventrally located intradural cystic lesion with apparent cord compression at C2-C3 level (Fig. 2).

With the patient in prone position, a cervical midline incision was made at the appropriate levels. En-block laminotomy of $\mathrm{C} 2$ and $\mathrm{C} 3$, incising the corresponding laminas bilaterally with the aid of high speed drill was done. The dura seemed under considerable pressure. The techal sac was open in the midline. This revealed a splayed cord under considerable pressure from the anterior. After sectioning dentate ligament on the right side
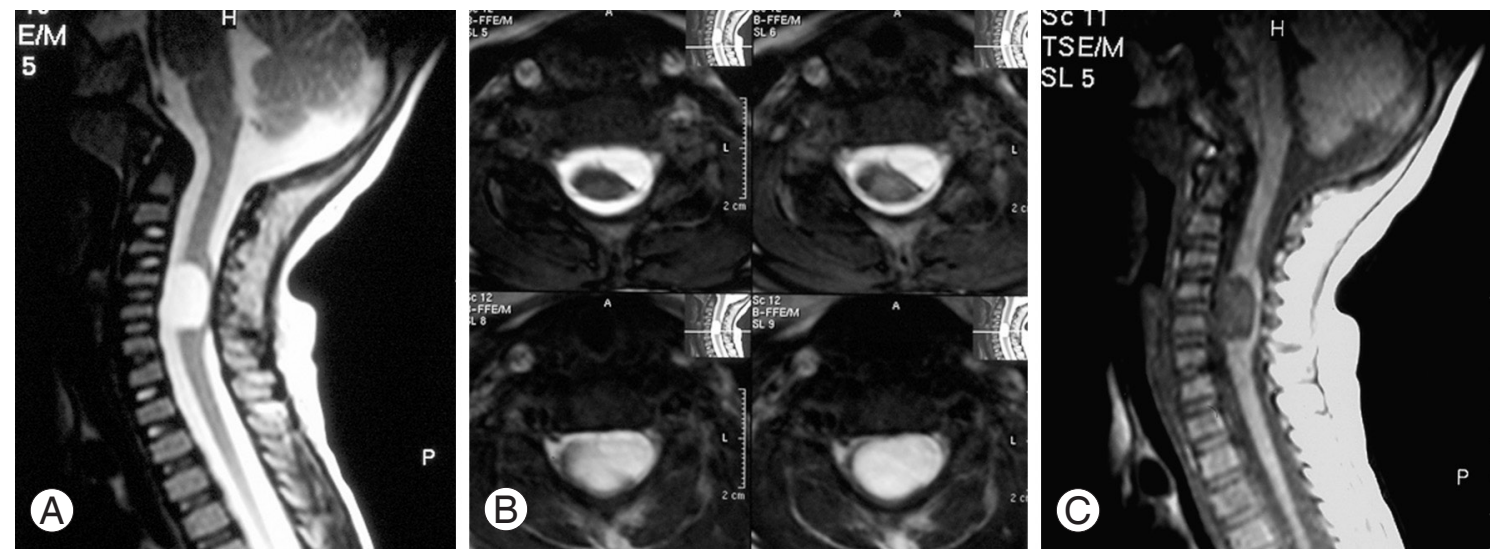

Fig. 1. (A) T2 magnetic resonance (MR) images of case one; sagittal view showing hyperintense mass anterolateral to the cord at C5-C6 level. (B) Axial view, showing the left anterolateral location of the cyst. (C) T1-weighted MR image demonstrating hypointense cyst at C5-C6 level of the same patient.
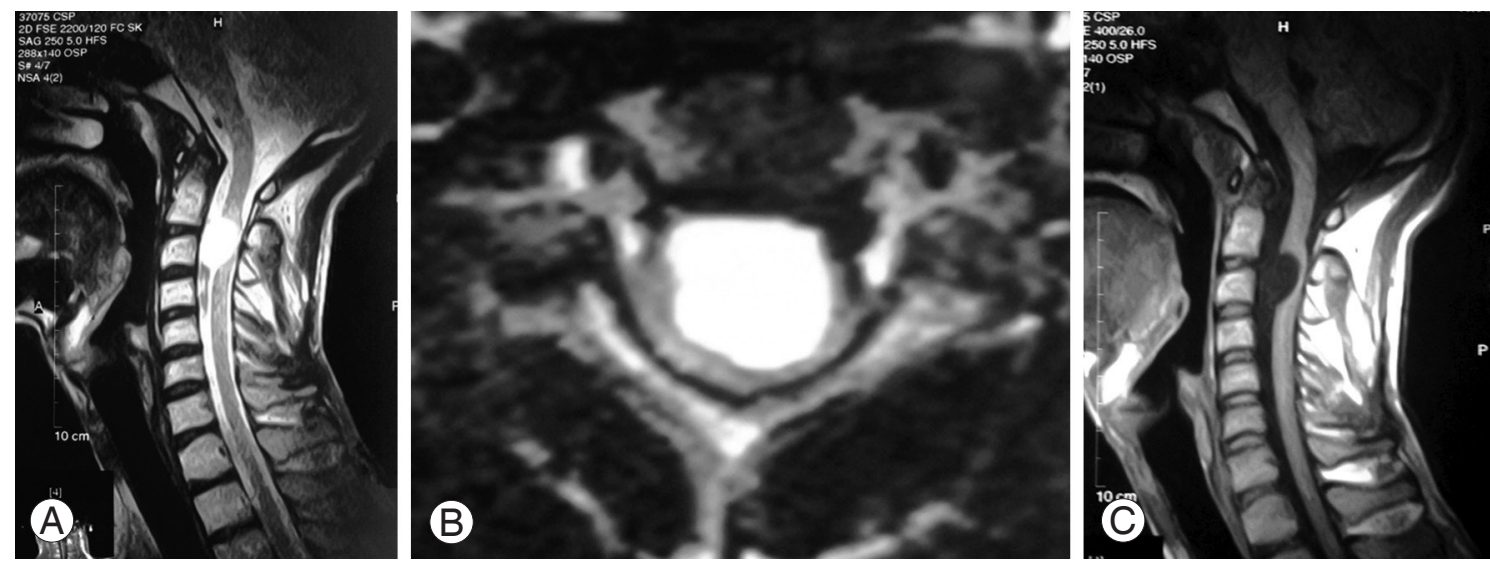

Fig. 2. (A, B) T2 magnetic resonance (MR) images of the second case showing an anteriorly located hyperintense mass compatible with a cyst at C2-C3 level. (C) T1-weighted MR image of the second case showing a hypointense mass. 
and mild retraction of the cord, a cystic mass with transparent wall became visible. The wall of the cyst was minimally incised disclosing clear content compatible with CSF. Subsequently, the cyst was widely fenestrated into the subarachnoid space with partial removal of the capsule (Fig. 3). The cord was decompressed and returned to its normal position with good pulsation. Later, after dural closure, two level laminoplasty with application of mini plates was done bilaterally (Figs. 4, 5). The patient made uneventful recovery and post operative cervical
MRI showed resolution of the arachnoid cyst (Fig. 6). He returned to his previous activities within six months.

\section{Discussion}

Intradural arachnoid cysts are uncommon and most of them are located in the thoracic region followed with the lumbar and the cervical region [1,2]. Majority of these cysts lie posteriorly on the spinal cord and are rarely located anteriorly. Review of the literature revealed that
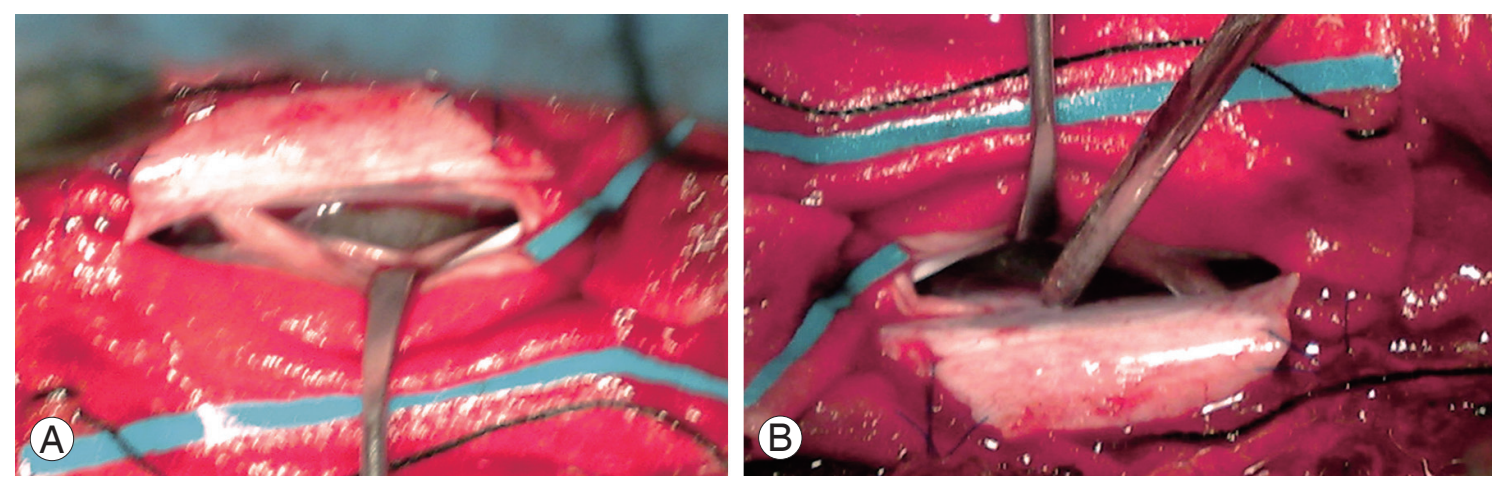

Fig. 3. (A) Intraoperative view showing a grayish translucent cyst in front of the cord. (B) The cyst is more clearly seen in this view.

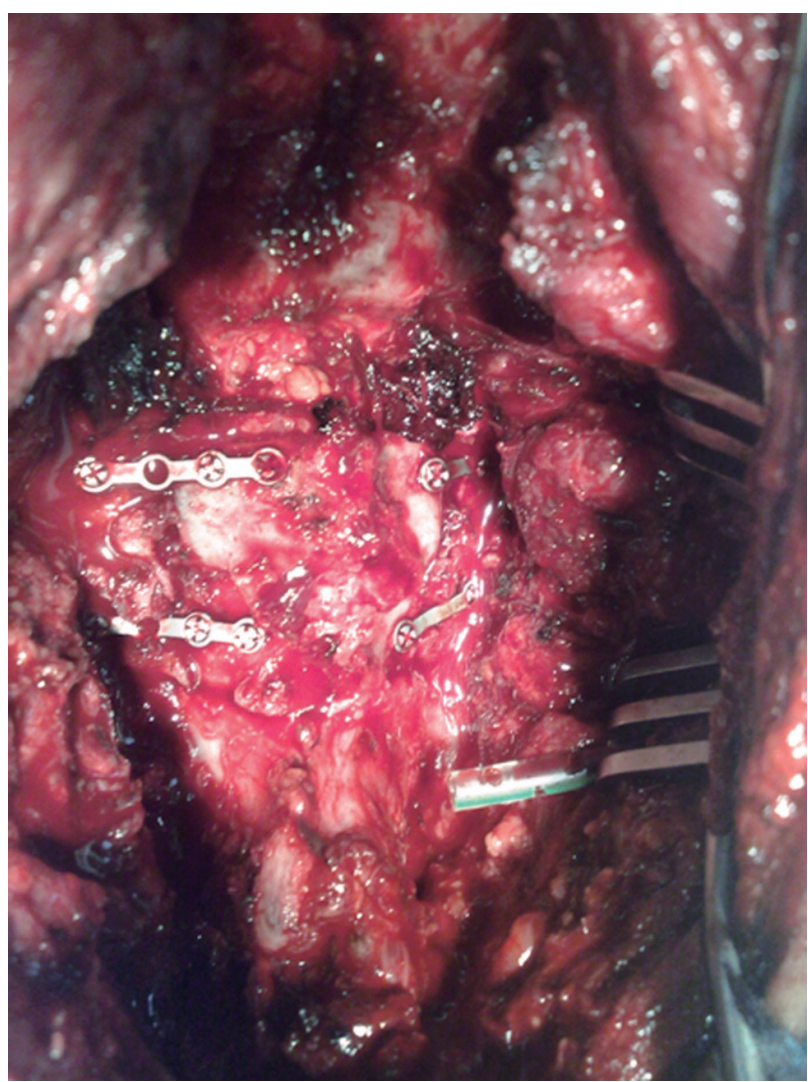

Fig. 4. Intraoperative view after laminoplasty.

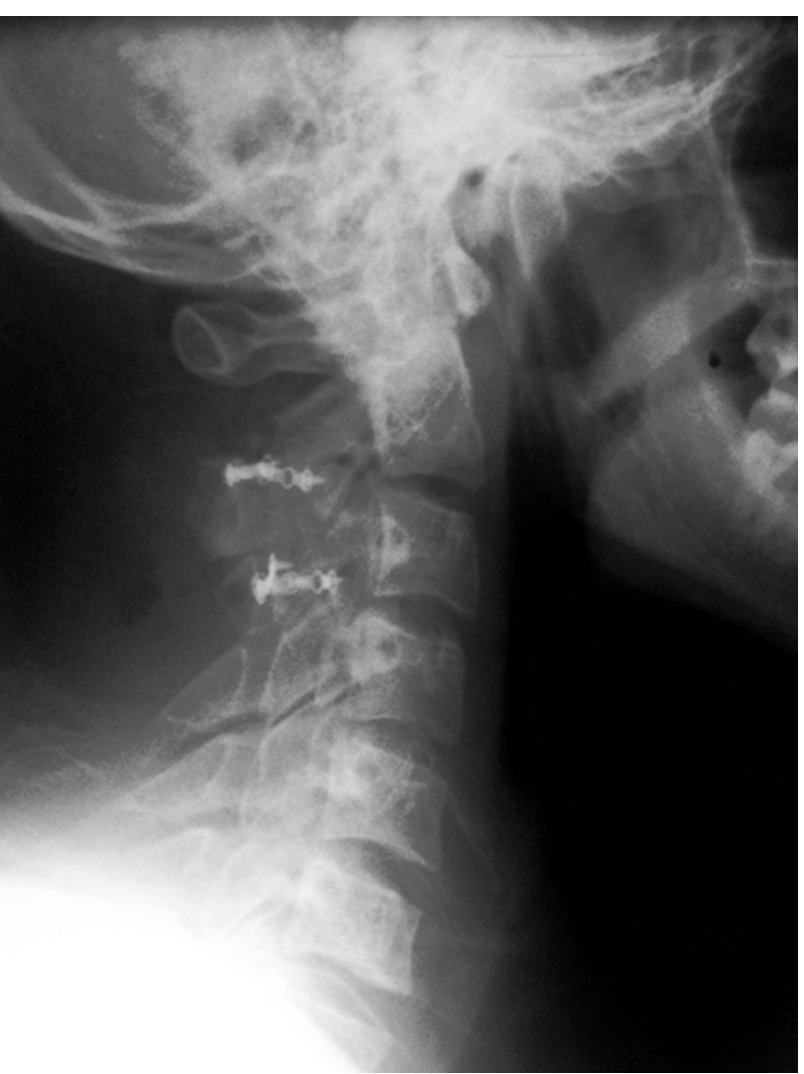

Fig. 5. Postoperative X-ray showing laminoplasty. 
anteriorly located intradural arachnoid cyst are very rare in the cervical region and we could find only 24 examples reported previously. With taking to account two current cases, the number of the cases published so far in the literature reach to 26 cases (Table 1).

Of the total these 26 reviewed cases, 15 occurred in males and the remaining 11 were female. Age ranged from 2 to 43 years with mean of $15 / 1$ years. In 19 cases the cyst was detected in the first two decade of life [3$7,11-13,17]$. Four cases were diagnosed in the third decade $[8,14,15,19]$. Two patients in the forth decade and one in his fifth decade became symptomatic $[1,9,18]$.

Most of these arachnoid cysts were considered congenital, however minor or major trauma was suspected to play a role in five instances $[3,4,17,22]$. Trauma might take part in the pathology and semiology of intradural arachnoid cysts in two ways: either by producing a breach in the arachnoid membrane and subsequent development of a cyst or may trigger a silent preexisting arachnoid cyst into a symptomatic one.

The cyst occupied one or two vertebral segments in majority $[3-6,8,11,13,16,17,21,22]$. But it extended full cervical length from foramen magnum to lower cervical region in five occasions $[9,12,18,19]$.

From clinical point of view, neck pain or wry neck are prominent symptom, but concurrence of weakness of upper or lower extremity of one or two weeks duration makes the patients or their parents to seek medical advice in our survey 38.5\% of the cases had neck pain. Quadriparesis was the most frequent sign seen in $50 \%$ of the

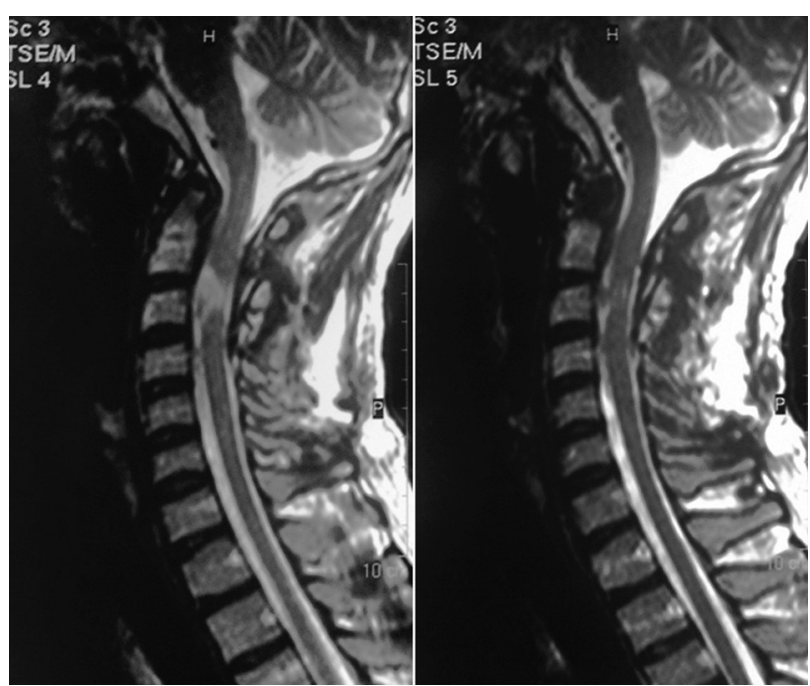

Fig. 6. Postoperative T2-weighted magnetic resonance sagittal images of the cervical spine showing near to complete resolution of the cyst. patients. Torticollis in our first case seems to be a compensatory event made for free passage of CSF.

In pre MRI era, myelography and computed tomography (CT) myelography were used to diagnose these lesions $[1,3,7]$. In conventional myelogram, displacement and compression of the spinal cord was visualized. However, the arachnoid cyst could have been filled only in supine delayed myelogram. With regard to CT, CSF attenuation may be recognizable on plain CT scans using rapid high resolution machines, but intrathecal metrizamide is almost always necessary to confirm and elucidate the details $[3,7]$.

MRI is the modality of choice in diagnosis of the anterior cervical arachnoid cysts being demonstrated as a low signal round or oval lesions in T1 and hyperintense mass in T2 images compatible with CSF. Nowadays, with increased application of MRI, the numbers of the intradural arachnoid cysts are reported in increasing frequency and in earlier stage of cord compression. Twelve out of 26 reviewed cases were diagnosed in post MRI era [13-21].

In differential diagnosis of such unusual cysts in such a rare location, arachnoid cysts secondary to arachnoiditis should be born in mind. Developments of such ventrally located cysts after bacterial or tuberculous meningitis have been reported in the cervical region quite resembling congenital arachnoid cysts [23]. Entrogenous cysts also known as edodermal cysts might express themselves with the same MRI features similar to arachnoid cysts and final diagnosis can be only made intraoperatively $[24,25]$. Intradural spinal parasitic cysts such as cysticercosis and hydatid cyst, although rare but should remain in differential diagnosis of arachnoid cysts specially in endemic areas [26,27].

Surgery is indicated once an intradural arachnoid cyst is suspected. The first step is laminectomy or laminoplasty, Nowadays en block laminoplasty is suggested to avoid postoperative kyphosis. This procedure is mostly and particularly recommended in the patients with cervical and cervicothoracic intradural cysts and tumors. Although children are more expected to develop postlaminectomy kyphosis but this deformity is not uncommon in adults. Subsequent to dural opening and minimal cord retraction, the cyst can be reached. In this stage, although complete surgical excision of the cyst seems desirable but it is not possible in all instances because of the scarring and adherence of arachnoid membrane to the cord. However, wide fenestration and partial removal 
Table 1. Ventral cervical arachnoid cyst

\begin{tabular}{|c|c|c|c|c|c|c|}
\hline Author & Year & $\begin{array}{l}\text { Age }(y r) / \\
\text { Sex }\end{array}$ & Symptom & Location & Surgery & Outcome \\
\hline Hoffman et al. [4] & 1960 & $6 / \mathrm{M}$ & Flaccid quadriparesis & C2-C3 & Laminectomy+resection & Improved \\
\hline Palmer [5] & 1974 & $19 / F$ & Spastic quadriparesis & C1-C3 & Laminectomy+cyst resection & Improved \\
\hline Palmer [6] & 1974 & $3 / \mathrm{M}$ & Respiratory failure & $\mathrm{C} 2-\mathrm{C} 4$ & Laminectomy+ needle aspiration & Died \\
\hline Duncan and Hoare [7] & 1978 & $3 / F$ & Neck pain+hemiparesis & $\mathrm{CO}-\mathrm{C2}$ & Laminectomy+resection & Improved \\
\hline Herskowitz [8] & 1978 & $28 / F$ & Spastic quadriparesis & C6-C7 & Laminectomy+cyst resection & Improved \\
\hline Kendall et al. [1] & 1982 & $31 / F$ & Spastic paraplegia & С5-С7 & Laminectomy+cyst resection & Not improved \\
\hline Chan et al. [9] & 1985 & $37 / \mathrm{M}$ & Upper extremity weakness & CO-L5 & Cystoperitoneal shunt & Improved \\
\hline Jena et al. [10] & 1990 & $17 / \mathrm{M}$ & Spastic quadriparesis & C7-T1 & Laminectomy+cyst resection & Improved \\
\hline Rabb et al. [11] & 1992 & $2 / F$ & Spastic quadriparesis & C6-C7 & Cystopleural shunt & Improved \\
\hline Chen and Chen [22] & 1996 & 18/M & Hemiparesis & C3-C7 & Laminectomy+cyst resection & Improved \\
\hline Jean et al. [12] & 1998 & $14 / \mathrm{F}$ & Headache vertigo & CO-C6 & Cystoperitoneal shunt & Improved \\
\hline Jean et al. [12] & 1998 & $9 / \mathrm{M}$ & Neck pain+quadriparesis & СО-С5 & Aspiration+reservoir & Improved \\
\hline Kazan et al. [3] & 1999 & 18/M & Neck pain+quadriparesis & C6-C7 & Laminectomy+cyst excision & Improved \\
\hline Kazan et al. [3] & 1999 & $2 / F$ & Neck pain+quadriparesis & C2-C3 & Laminectomy+cyst excision & Improved \\
\hline Lee and Cho [13] & 2001 & $9 / \mathrm{M}$ & Paraparesis & С5-Т1 & Laminectomy+cyst excision & Improved \\
\hline Safriel et al. [14] & 2002 & 26/M & Left hemiparesis & С5-Т3 & Laminectomy+cyst excision & Improved \\
\hline Banczerowski et al. [15] & 2003 & $22 / \mathrm{M}$ & $\begin{array}{l}\text { Neck pain Rt. upper, monop- } \\
\text { araesthesia }\end{array}$ & C6-C7 & Corpectomy cyst excision & Improved \\
\hline Takahashi et al. [16] & 2003 & 13/M & Neck \& occipital pain & C1-C3 & $\begin{array}{l}\text { Magnetic resonance imaging } \\
\text { guided aspiration }\end{array}$ & Improved \\
\hline Muthukumar [17] & 2004 & $4 / \mathrm{M}$ & Quadriparesis & C3-C4 & Laminectomy+cyst excision & Improved \\
\hline Muthukumar [17] & 2004 & $14 / F$ & Quadriparesis & C6-C7 & Laminectomy+cyst excision & Improved \\
\hline Maiuri et al. [18] & 2006 & $43 / F$ & $\begin{array}{c}\text { Neck pain+recurrent quadri- } \\
\text { paresis }\end{array}$ & Co-C7 & Laminectomy, cyst excision & Improved \\
\hline Gezici and Ergun [19] & 2008 & $2,1 / 2 \mathrm{M}$ & Neck stiffness quadriparesis & $\mathrm{CO}-\mathrm{C} 7$ & $\begin{array}{l}\text { Laminectomy, wide } \\
\text { fenestration+excision }\end{array}$ & Improved \\
\hline Campos et al. [20] & 2008 & $5 / F$ & $\begin{array}{c}\text { Neck pain+upper extremity } \\
\text { monoparesis }\end{array}$ & C1-C2 & Laminectomy, cyst wide resection & Died \\
\hline Muhammedrezai et al. [21] & 2008 & 29/M & Paraparesis & C7 & Corpectomy+cyst excision & Improved \\
\hline Present cases & 2012 & $2 / F$ & $\begin{array}{l}\text { Neck pain+torticollis+left } \\
\text { upper monoparesis }\end{array}$ & С5-C6 & Laminectomy+cyst excision & Improved \\
\hline Present case & 2012 & $17 / \mathrm{M}$ & $\begin{array}{l}\text { Neck pain+torticollis+ } \\
\text { quadriparesis }\end{array}$ & C2-C3 & Laminopalsty+cyst excision & Improved \\
\hline
\end{tabular}


of the cyst allowing maximal communication of the cyst with subarachnoid spaces is an accepted mode of surgery and has been applied in $69 \%$ of the reported cases with success. Recurrence might be expected if insufficient fenestration or aspiration alone is used $[6,12]$. Cystoperitoneal or cystopleural shunt might be used as a primary mode of surgery or in recurrences $[9,11,12]$. Intermittent aspiration with application of percutaneous reservoir was use in one occasion [12]. Despite of previous reports on recurrence and even death with aspiration [5]. There is one report of image guided aspiration with good recovery [16]. However, we do not recommend aspiration as an acceptable modality of treatment regarding the fact that the arachnoid cysts of different types and locations mostly recur after aspiration

In order to obviate the need for cord retraction, anterior approach through cervical body vertebrectomy has been suggested and done in two separate reports $[15,21]$. But, since majority of these cysts can be easily accessed through the posterior approach without morbidity, the issue of anterior approach should be remained open for discussion.

Prognosis for complete recovery should be expected with excellent outcome, especially if the arachnoid cysts are diagnosed early.

Ultimately, this conclusion was made that anteriorly located arachnoid cyst of the cervical region should be considered in children and young adults with neck pain or torticollis specially if these are followed with motor weakness. Surgery should be done as soon as the diagnosis is made, nowadays, complete recovery after surgery should be expected and despite of lack of any report on postoperative kyphosis in laminectomized cases, laminoplasty is strongly recommended in children in order to avoid post-laminectomy deformity.

\section{Conflict of Interest}

No potential conflict of interest relevant to this article was reported.

\section{References}

1. Kendall BE, Valentine AR, Keis B. Spinal arachnoid cysts: clinical and radiological correlation with prognosis. Neuroradiology 1982;22:225-34.

2. Alvisi C, Cerisoli M, Giulioni M, Guerra L. Long- term results of surgically treated congenital intradural spinal arachnoid cysts. J Neurosurg 1987;67:3335.

3. Kazan S, Ozdemir O, Akyuz M, Tuncer R. Spinal intradural arachnoid cysts located anterior to the cervical spinal cord: report of two cases and review of the literature. J Neurosurg 1999;91:211-5.

4. Hoffman EP, Garner JT, Johnson D, Shelden CH. Traumatic arachnoidal diverticulum associated with paraplegia: case report. J Neurosurg 1973;38:81-5.

5. Palmer JJ. Spinal arachnoid cysts: report of six cases. J Neurosurg 1974;41:728-35.

6. Palmer JJ. Cervical intradural arachnoid cyst in a 3-year-old child: report of a case. Arch Neurol 1974;31:214-5.

7. Duncan AW, Hoare RD. Spinal arachnoid cysts in children. Radiology 1978;126:423-9.

8. Herskowitz J, Bielawski MA, Venna N, Sabin TD. Anterior cervical arachnoid cyst simulating syringomyelia: a case with preceding posterior arachnoid cysts. Arch Neurol 1978;35:57-8.

9. Chan RC, Thompson GB, Bratty PJ. Symptomatic anterior spinal arachnoid diverticulum. Neurosurgery 1985;16:663-5.

10. Jena A, Gupta RK, Sharma A, Prakesh VE, Khushu S. magnetic resonance diagnosis of spinal arachnoid cyst: a report of two cases. Childs Nerv Syst 1990;6:107-9.

11. Rabb CH, McComb JG, Raffel C, Kennedy JG. Spinal arachnoid cysts in the pediatric age group: an association with neural tube defects. J Neurosurg 1992;77:369-72.

12. Jean WC, Keene CD, Haines SJ. Cervical arachnoid cysts after craniocervical decompression for Chiari II malformations: report of three cases. Neurosurgery 1998;43:941-4.

13. Lee HJ, Cho DY. Symptomatic spinal intradural arachnoid cysts in the pediatric age group: description of three new cases and review of the literature. Pediatr Neurosurg 2001;35:181-7.

14. Safriel YI, Sanchez G, Jhaveri HS. Giant anterior cervicothoracic arachnoid cyst. Spine (Phila Pa 1976) 2002;27:E366-8.

15. Banczerowski P, Lipoth L, Vajda J, Veres R. Surgery of ventral intradural midline cervical spinal pathologies via anterior cervical approach: our experience. Ideggyogy Sz 2003;56:115-8. 
16. Takahashi S, Morikawa S, Egawa M, Saruhashi Y, Matsusue Y. Magnetic resonance imaging-guided percutaneous fenestration of a cervical intradural cyst. Case report. J Neurosurg 2003;99:313-5.

17. Muthukumar N. Anterior cervical arachnoid cyst presenting with traumatic quadriplegia. Childs Nerv Syst 2004;20:757-60.

18. Maiuri F, Iaconetta G, Esposito M. Neurological picture. Recurrent episodes of sudden tetraplegia caused by an anterior cervical arachnoid cyst. J Neurol Neurosurg Psychiatry 2006;77:1185-6.

19. Gezici AR, Ergun R. Cervical anterior intradural arachnoid cyst in a child. Acta Neurochir (Wien) 2008;150:695-8.

20. Campos WK, Linhares MN, Brodbeck IM, Ruhland I. Anterior cervical arachnoid cyst with spinal cord compression. Arq Neuropsiquiatr 2008;66:272-3.

21. Muhammedrezai S, Ulu MO, Tanriover N, Moghaddam AM, Akar Z. Cervical intradural ventral arachnoid cyst resected via anterior corpectomy with reconstruction: a case report. Turk Neurosurg 2008;18:241-4.
22. Chen HJ, Chen L. Traumatic interdural arachnoid cyst in the upper cervical spine. Case report. J Neurosurg 1996;85:351-3.

23. Lolge S, Chawla A, Shah J, Patkar D, Seth M. MRI of spinal intradural arachnoid cyst formation following tuberculous meningitis. Br J Radiol 2004;77:681-4.

24. Asazuma T, Sato M, Ichimura S, et al. Endodermal cyst of the cervical spine treated by an anterior approach for resection and shunting. J Spinal Disord Tech 2002;15:258-60.

25. Sasani M, Ozer AF, Oktenoglu BT, Peker K, Bozkus $\mathrm{MH}$, Sarioglu AC. Excision of an asymptomatic cervical intradural neurenteric cyst through the anterior approach: a study of two cases and a review of the literature. Spine J 2007;7:720-7.

26. Ciftci E, Diaz-Marchan PJ, Hayman LA. Intraduralextramedullary spinal cysticercosis: MR imaging findings. Comput Med Imaging Graph 1999;23:1614.

27. Pushparaj K, Sundararajan M, Madeswaran K, Ambalavanan S. Primary spinal intradural hydatid cyst: a short report. Neurol India 2001;49:203-4. 